\title{
Materialismo corticeiro
}

\author{
[Slummy materialism
}

\section{Lindberg S. Campos Filho}

RESUMO - Este é um breve exercício de leitura do romance emblemático do naturalismo brasileiro O cortiço (I890), de Aluísio Azevedo, levando em consideração a crítica produzida por Antonio Candido em "De cortiço a cortiço" (I974; I99I), ao mesmo tempo que levanta a hipótese de que alguns dos métodos de construção dessa narrativa podem ser lidos, em certa medida, como antecipações, ora mais ora menos conscientes, dos paradigmas de determinação social que guiariam a crítica cultural materialista ao longo do século seguinte. -PALAVRAS-CHAVE - O cortiço; Aluísio Azevedo; materialismo cultural; Antonio Candido. .
ABSTRACT - This is a brief reading exercise of the emblematic novel of Brazilian Naturalism "O cortiço" (I890) of Aluisio Azevedo, taking into account the criticism produced by Antonio Candido in "De cortiço a cortiço" (I974; I99I) at the same time which raises the hypothesis that some of the methods of constructing this narrative may be read, to some extent, the anticipations, sometimes more, sometimes less conscious, of the paradigms of social determination that would guide materialist cultural criticism over the next century. KEYWORDS · "O cortiço"; Aluísio Azevedo; cultural materialism; Antonio Candido.

Recebido em Io de outubro de 2018

Aprovado em 5 de novembro de 2019

CAMPOS FILHO, Lindberg S. Materialismo corticeiro. Revista do Instituto de Estudos Brasileiros, Brasil, n. 74, p. 25I-269, dez. 2019.

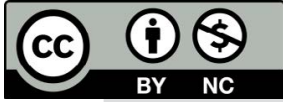

DOI: http://dx.doi.org/Io.II6o6/issn.23I6-90IX.voi74p25I-269

I Universidade de São Paulo (USP, São Paulo, SP, Brasil). 


\section{ANTES DE QUALQUER OUTRA COISA}

Apesar de nós podermos, no estudo de um período passado, separar aspectos particulares da vida, e tratá-los como se fossem autossuficientes, é óbvio que isto é apenas como eles podem ser estudados, não como eles foram experienciados.

Nós examinamos cada elemento como uma substância precipitada, mas na experiência viva do tempo todo elemento está em solução como uma parte inseparável de um todo complexo. E isso parece ser verdadeiro a partir da natureza

da arte, já que é a partir de tal totalidade que o artista se referencia; é na arte, primeiramente, que o efeito de toda uma experiência vivida é expresso e incorporado. (Raymond Williams, Drama from Ibsen to Brecht, p. 10 tradução nossa).

Poderíamos começar afirmando que as análises de obras particulares, por parte de Antonio Candido, são instantes privilegiados de sua trajetória intelectual, pois é precisamente através delas que enxergamos suas teses teóricas em pleno funcionamento. "De cortiço a cortiço" (I974; I99I) é, nesse sentido, um escrito exemplar e seminal, principalmente uma vez que opera aquela unidade entre teoria e prática que é tão almejada quanto difícil de ser executada. De fato, as linhas gerais de seus paradigmas de teoria e crítica literárias ficam evidentes logo de início: trata-se de um procedimento que não se contenta em apenas listar os materiais e arranjos, isto é, em operar, por melhor que fosse, uma mera descrição da estrutura técnica das obras. Candido, em vez disso, propõe que prestemos atenção também ao próprio processo de estruturação das obras, salientando as feições sociais dessa estrutura. Isso se deve ao fato de ser na reconstrução desse movimento preliminar que teremos acesso ao que Candido chama de redução estrutural ou formalização estética dos dados externos - ou sócio-históricos -, tornando-os, desse modo, também internos, já que seriam submetidos a leis próprias à obra. Ou seja, essa seria a maneira pela qual poderíamos compreender 
a formação da obra, explicitando a relação não manifesta entre forma literária e processo social. Talvez seja produtivo passar a palavra para o professor:

\begin{abstract}
De fato, antes procurava-se mostrar que o valor e o significado de uma obra dependiam de ela exprimir ou não certo aspecto da realidade, e que este aspecto constituía o que ela tinha de essencial. Depois, chegou-se à posição oposta, procurando-se mostrar que a matéria de uma obra é secundária, e que a sua importância deriva das operações formais postas em jogo, conferindo-lhe uma peculiaridade que a torna de fato independente de quaisquer condicionamentos, sobretudo social, considerado inoperante como elemento de compreensão.

Hoje sabemos que a integridade da obra não permite nenhuma dessas visões dissociadas; e que só a podemos entender fundindo texto e contexto numa interpretação dialeticamente íntegra, em que tanto o velho ponto de vista que explicava pelos fatores externos, quanto o outro, norteado pela convicção de que a estrutura é virtualmente independente, se combinam como momentos necessários do processo interpretativo. Sabemos, ainda, que o externo (no caso, o social) importa não como causa, nem como significado, mas como elemento que desempenha um certo papel na constituição da estrutura, tornando-se, portanto, interno. (CANDIDO, 2006, p. I3-I4).
\end{abstract}

Uma conclusão inicial, que se pode extrair de tal modo de ler e de interpretar, repousa sobre a preocupação de conferir à obra um status de relativa autonomia em relação ao todo social. É justamente por isso que, apesar de seu processo de estruturação contar essencialmente com conteúdos e formas externos, ao serem articulados e organizados internamente, eles acabam por se subordinar a leis próprias à obra, desenvolvendo, assim, a semiautonomia da qual falávamos.

Caso olhemos agora para o objetivo primordial deste escrito - que é a identificação de correspondências na transição das escolas literárias realistas e naturalistas do século XIX para a crítica cultural materialista subsequente -, podemos enxergar nesse pressuposto um edifício crítico usado para conduzir as leituras que faremos a partir de agora. Talvez seja possível adiantar que o "método", caso ainda não tenha ficado evidente, é menos intuitivo do que dedutivo, pois ele é dado pelo objeto de análise - os materiais, e as suas disposições correspondentes, são eles mesmos imanentes e direcionam a crítica. Isso equivale a dizer que é a partir da configuração formal de uma dada obra que se encontra o caminho para enxergar o seu processo de estruturação; a sua aparição fenomênica, desse ponto de vista, conteria traços ou reminiscências da sua formação ou estruturação. Esses pressupostos parecem buscar certo equilíbrio dialético com o intuito de não ignorar não apenas condicionamentos, mas também imprevisibilidades inerentes ao fazer artístico, bem como de produzir uma análise que abarque tanto o projeto (obra) quanto a sua respectiva formação (circunstâncias sócio-históricas) indissociavelmente.

Vejamos agora como a caracterização do naturalismo é realizada por seu intérprete brasileiro mais conhecido, Aluísio Azevedo, e pelas lentes de Antonio Candido ao se aproximar da obra. 


\section{NATURALISMO À BRASILEIRA}

Mas então, ele, Miranda, que se supunha a última expressão

da ladinagem e da esperteza; ele, que, logo depois do seu casamento, respondendo para Portugal a um ex-colega que o felicitava, dissera que o Brasil era uma cavalgadura carregada de dinheiro, cujas rédeas um homem fino empolgava facilmente; ele, que se tinha na conta de invencível matreiro, não passava afinal de um pedaço de asno comparado com o seu vizinho! Pensara fazer-se senhor do Brasil e fizera-se escravo de uma brasileira mal-educada e sem escrúpulos de virtude! Imaginara-se talhado para grandes conquistas, e não passava de uma vítima ridícula e sofredora!... Sim! No fim de contas qual fora a sua África?... Enriquecera um pouco, é verdade, mas como? A que preço? [...] Arranjara a vida, sim, mas teve de aturar eternamente uma mulher que ele odiava! $E$ do que afinal the aproveitara tudo isso? Qual era afinal a sua grande existência? Do inferno da casa para o purgatório do trabalho e vice-versa! [...] A virtude, a beleza, o talento, a mocidade, a força, a saúde, e principalmente a fortuna, eis o que ele não perdoava a ninguém, amaldiçoando todo aquele que conseguia o que ele não obtivera; que gozava o que ele não desfrutara; que sabia o que ele não aprendera. E, para individualizar o objeto do seu ódio, voltava-se contra o Brasil, essa terra que, na sua opinião, só tinha uma serventia: enriquecer os portugueses, e que, no entanto, o deixara, a ele, na penúria. (Aluísio Azevedo, $O$ cortiço, p. 29).

Na epígrafe acima vemos como uma das personagens centrais de $O$ cortiço (I890), o português Miranda, é apresentada, mobilizando algumas das características mais típicas da "internacional naturalista", tal como a zoomorfização (o Brasil é uma cavalgadura, Miranda é um pedaço de asno), a forte determinação do meio e dos processos materiais, o desencantamento do mundo através da linguagem crua e direta, a qual muitas vezes beira o baixo calão etc. Percebemos ainda um movimento não incomum nesse romance que é o deslocamento da narração onisciente para o ponto de vista de uma personagem, deixando-a desabafar diretamente para o leitor, o que termina por produzir uma espécie de monólogo interior extremamente revelador e relevante para o eixo da obra. Primeiramente porque mostra o grau de consciência - ou seria melhor dizer pragmatismo, desfaçatez e cinismo por parte do europeu em relação a este lugar? - e, em segundo lugar, porque demonstra que as ilusões a serem perdidas por aqui dificilmente seriam da mesma ordem que aquelas a serem perdidas na Europa; tais coordenadas, portanto, exigiriam do romancista local todo um rearranjo da forma recebida. Isso pode ser dito porque é exatamente essa relação de Miranda e de João Romão com o Brasil que fará com que a obra de Aluísio Azevedo se coloque em um outro patamar, especialmente caso a comparemos 
com L'assommoir (I877), de Émile Zola. Em suma, o naturalismo europeu não poderia continuar o mesmo ao desembarcar na jovem nação periférica, apenas virtualmente independente e que havia passado por ao menos 300 anos de colonialismo; aqui o materialismo naturalista jamais poderia ficar cativo da sua expressão metropolitana, porque, como diz a sabedoria popular, o buraco é mais embaixo.

Desse modo, não é à toa que Aluísio Azevedo seja comumente visto como uma espécie de artífice da escola naturalista no Brasil. No entanto, se o naturalismo for entendido estritamente como uma rebelião contra os princípios mais específicos da estética romântica herdada pelo século XIX, difusamente dominantes até então - como, por exemplo, a sua preocupação com o abandono da idealização, do supernatural e do sentimentalismo por um maior apego à materialidade, certo cientificismo e racionalidade -, será fatalmente redundante revisitar um conjunto de características autoevidentes, principalmente do ponto de vista contemporâneo. Nesse sentido, por mais sedutor e, em certa medida, verdadeiro que seja esse esquema, ele não nos leva muito longe na compreensão do romance, pois nos permite fazer pouca coisa além de buscar a confirmação daqueles parâmetros gerais já sabidos de antemão. Pior ainda: irremediavelmente caímos na posição de enxergar a produção brasileira sempre de um prisma subalterno à produção metropolitana.

Dito isso, da nossa perspectiva, o que mais confere interesse à análise de Antonio Candido de $O$ cortiço é precisamente que ele declara desde o início que, em vez de meramente reafirmar as convergências entre a matriz europeia e a realização local, o crítico também vai verificar certa originalidade no que antes poderia aparecer como simples imitação; é essa pista deixada por ele que vamos seguir. De fato, Candido vai desenvolver uma dialética concebendo a obra emblemática do naturalismo à brasileira como, a um só tempo, texto primeiro e texto segundo: "texto primeiro na medida em que filtra o meio; texto segundo na medida em que vê o meio com lentes tomadas de empréstimo, $O$ cortiço é um romance bem realizado [...] pelo encontro feliz dos dois procedimentos" (CANDIDO, 20I5, p. I09). Diga-se, só de passagem, que a genealogia desse ensaio de Candido em si revela um dado no mínimo curioso: se por um lado nos anos I970 - quando ele primeiramente surgiu - seu objetivo principal era contrapor a dialética ao método estruturalista de análise de obras, notadamente aquele de Análise estrutural de romances brasileiros (I973) de Affonso Romano de Sant'Anna, problematizando a fidelidade aos respectivos contextos dos textos, por outro lado o escrito que aparece nos anos I990, e que sofre algumas alterações nos anos 2000, enfatiza o problema da filiação, sempre colocando no centro menos a transposição geográfica do que a relação indissociável entre produção literária e formação social. Isto é, na evolução da escrita de Candido, à medida que a polêmica com o estruturalismo perde força, ganha energia o confronto ideológico no qual Zola e Azevedo estavam inseridos, a saber, a "exploração do trabalho urbano e a mercantilização do espaço físico, em particular da habitação" (SEREZA, 20I2, p. 28-29).

Feita esta breve nota, voltemos à reconstrução do argumento de Candido, já na sua última versão. Ao se deixar guiar pela dinâmica da matéria social brasileira, diz nosso crítico, ainda que lançando mão de ferramentas estrangeiras para fazê-lo, Azevedo acaba construindo um ponto de vista mais particular, o que redunda em um ganho em especificidade. Além disso, talvez seja possível afirmar - e muito 
provavelmente esta seja a possível contribuição singela que este breve estudo possa fazer no caso de ser bem-sucedido - que tanto os paradigmas mais gerais da matriz europeia do naturalismo quanto os seus desdobramentos brasileiros nas mãos de Aluísio Azevedo colocaram em movimento muitos dos assuntos e dos métodos a que a crítica de pretensões materialistas se dedicou ao longo do século seguinte. Evidentemente que não somente em termos do que se poderia e deveria fazer, mas também em relação ao que se deveria rejeitar e superar, estabelecendo, portanto, uma espécie de marco referencial no trato da matéria social.

Pensemos, em primeiro lugar, algo que é de fundamental importância para o naturalismo de Azevedo e igualmente para a crítica materialista que se forma mais tarde: as dinâmicas específicas do processo de acumulação do capital em um país como o Brasil e da estrutura de classes desse determinado meio social. Com efeito, parece que é levando em consideração isso que Candido reconhece que

\begin{abstract}
Aluísio foi, salvo erro meu, o primeiro dos nossos romancistas a descrever minuciosamente o mecanismo da riqueza individual. Basta comparar o seu livro com as indicações sumárias de Macedo, Alencar ou Machado de Assis, nos quais o dinheiro aparece com frequência, mas adquirido por herança, dote ou outra causa fortuita. Pesando, determinando, é certo, mas como um dado já pronto no entrecho. N'O cortiço ele se torna implicitamente objeto central da narrativa, cujo ritmo acaba se ajustando ao ritmo da sua acumulação, tomada pela primeira vez no Brasil como eixo da composição ficcional. (CANDIDO, 20I5, p. II3-II4).
\end{abstract}

Do ponto de vista da arte ocidental subsequente do século XX, o naturalismo, incluindo o que chamamos de naturalismo à brasileira de Aluísio Azevedo, tem como legado não apenas aspectos da ordem da tematização das situações dos pobres, mas também os experimentos de como representar essas situações de maneiras mais adequadas. Afinal, cabe lembrar, a forma do diálogo interindividual eloquente no quadro da vida privada ou a da tomada de decisão do indivíduo quase que completamente dono do seu destino não pareciam apropriadas para representar os de baixo, sobretudo tendo em vista a praticamente ausência de propriedade, de margem de manobra, e uma vez que estavam em grande medida política e economicamente dependentes do arbítrio dos de cima em meio a uma sociedade onde o trabalho assalariado livre ainda começava a se articular. É nesse sentido que $O$ cortiço ensaia inúmeras possibilidades de representação da classe - enquanto classe não organizada, é bom que não se esqueça -, que nem ao menos tinha o direito à representação, pensando-a dentro do quadro da acumulação do capital e seus integrantes como pouca coisa além de meros joguetes desse mesmo processo. Isso sem mencionar que é perfeitamente plausível defender que o romance conseguiu captar uma tendência de crescente desumanização generalizada, alçando até mesmo o proprietário à condição de objeto da propriedade, ou objeto do objeto, gerando a reificação ou "coisificação" típica da estruturação de classes sob a égide da dominância da forma mercantil. Em outras palavras, Azevedo procura não apenas estudar os pobres, mas também reproduzir literariamente o processo de aburguesamento disponível para certos indivíduos no contexto brasileiro oitocentista, que conseguiram "se fazer" por aqui. 
A trajetória de João Romão é paradigmática nesse sentido, porque através dele vemos que, diferentemente da "formação" mais ou menos tradicional do burguês europeu, incluindo aí suas ansiedades e expectativas, no Brasil tudo isso sofria um rebaixamento que estava em sintonia com a menor circulação de capital em uma ex-colônia não industrializada, mas que, mesmo assim, passava por uma onda de modernização conservadora. João Romão e até mesmo o mais bem afortunado Miranda são ilustrações de como por aqui os meios e os resultados do aburguesamento poderiam ter como solução estética uma espécie de "caricatura da caricatura”, já que se tratava de uma caracterização de segundo grau; isto é, o arquétipo do burguês avarento europeu sofreu uma mutação local, tendo em vista que grande parte do excedente propiciado pela estrutura econômica colonial e baseada no trabalho escravo tinha como destino preferencial os fluxos de capitais que desembocavam nos países metropolitanos: não deve ser visto como acaso o fato do romance não ser ambientando em uma fábrica, mas em um cortiço, e ele mesmo ser o meio de produção econômica central no romance, o que, de certa maneira e ao mesmo tempo, repõe e antecipa a dilatação de modos de acumulação especulativa onde há ausência ou menor presença de modos de acumulação mais propriamente produtivos. Mais ainda: o final trágico para a escravizada Bertoleza bem como a "expulsão" dos corticeiros para dar lugar a uma avenida com pessoas um pouco acima na escala social não são desfechos propriamente hiperbólicos ou alegóricos, mas precisos e literais caso usemos as dinâmicas da realidade brasileira como régua e compasso.

No que diz respeito à figuração de classe dos pobres, pode-se argumentar que o romance se apega às determinações sociais que envolvem o indivíduo: isso significa que para representá-los também seria fundamental reconstruir o meio de onde eles emergiam mesmo que fosse indiretamente e emulando as condições subalternas que essa menor quantidade de valor para distribuir ensejava. Ou seja, a centralidade do meio e da propriedade recoloca determinações históricas da ascensão do proletariado, a qual dependeu, tanto no Brasil quanto na Europa, justamente da concatenação entre o primado da propriedade privada e da acumulação de capitais, ainda que fosse em estado muito primitivo por aqui nos anos 1890. No romance de Azevedo a origem do grosso do povo brasileiro tem uma ambientação que troca as praias paradisíacas e as matas virgens por onde flutuava a Iracema de José de Alencar pelo olhar atento e premonitório da união entre miséria e natureza tropical:

E naquela terra encharcada e fumegante, naquela umidade quente e lodosa, começou a minhocar, a esfervilhar, a crescer, um mundo, uma coisa viva, uma geração, que parecia brotar espontânea, ali mesmo, daquele lameiro, e multiplicar-se como larvas no esterco. E durante dois anos o cortiço prosperou de dia para dia, ganhando forças, socando-se de gente. E ao lado o Miranda assustava-se, inquieto com aquela exuberância brutal de vida, aterrado defronte daquela floresta implacável que lhe crescia junto da casa, por debaixo das janelas, e cujas raízes, piores e mais grossas do que serpentes, minavam por toda parte, ameaçando rebentar o chão em torno dela, rachando o solo e abalando tudo. (AZEVEDO, 20I6, p. 27-28).

Acima vemos como o materialismo do naturalismo se mostrou sensível à 
determinação da configuração do meio social e natural na formação de uma nova classe. Uma classe social não proprietária e que tinha como atributo embutido no seu próprio nome a sua "multiplicação" na forma da prole. Igualmente é possível perceber como a miséria dessa classe é, contraditoriamente, atrelada à prosperidade da acumulação de capitais que, no caso, se dá a partir do arrendamento da propriedade por parte de João Romão. Porém, ao mesmo tempo, não é difícil enxergar que a expansão do mundo dos pobres sem propriedade gera uma contradição crescente e que termina por representar um grave perigo para os proprietários, fazendo-os, literalmente, perder o sono. É óbvio que, por mais verdadeira que seja toda a construção acima, ela não deixa de padecer dos males advindos do fato de ela ser deveras alegórica, o que, portanto, a faz não somente perder especificidade, mas também sucumbir à primazia da descrição em detrimento da explicação. Em outras palavras, embora esse procedimento seja extremamente louvável e profícuo, sobretudo se for localizado dentro do quadro maior de luta dos trabalhadores por representação na literatura - da qual o naturalismo é um capítulo -, não se deve perder de vista as suas insuficiências em relação à complexidade da matéria histórica.

Daí uma tensão tipicamente oitocentista de idealizar ou de objetificar excessivamente o pobre na sua representação genérica e que, a bem da verdade, o naturalismo procurou superar ainda que com sucesso parcial, pois a evidente objetificação dos indivíduos primeiramente conduzia a certa hipervalorização de uma solidariedade humanista e pouco consequente no que tange à superação daquela dada situação dos pobres, recriando condições do inflacionamento da passividade das vítimas, de idealização delas ou até mesmo de certo paternalismo ou de tolerância em relação à miséria. Dito em outros termos, a concepção mecânica a partir da qual pobres, proprietários e seus respectivos espaços no todo social são produtos de processos impessoais e materiais se mostrou imensamente ambivalente porque, se por um lado há verdade na premissa de que, especialmente no capitalismo, seres humanos e coisas são da mesma natureza e portanto têm seus atos de vontade individual reduzidos em alcance e em possibilidade, por outro lado, não se pode perder de vista que este é somente o ponto de chegada do positivismo (descrição e explicação mecânicas da realidade tal como ela se apresenta), o qual não consegue enxergar que essa relação é muito mais complexa tanto na sua heterogeneidade quanto na sua homogeneidade. A propósito, vale lembrar, a crítica da economia política marxista não buscou superar meramente o liberalismo clássico, mas também a visão cientificista reificada do positivismo: não seria o segredo da mercadoria e, portanto, da produção de capital, justamente o dispêndio de energia vital ou trabalho humano? Isto é, o trabalho e o trabalhador são, sem sombra de dúvida, vítimas, mas também agentes do fetichismo da mercadoria que, por sua vez, objetiva e subjetivamente sustentam a ordem moderna.

O que é discutível, como pontuado acima, embora um pouco compreensível, é o caráter passivo das massas trabalhadoras, as quais aparecem como meros objetos apáticos da acumulação, apesar de já terem demonstrado alguma capacidade organizativa na época. Isso também esbarra na ausência do capital industrial tanto no romance quanto na efetividade brasileira, o que impõe uma dinâmica ainda mais desfavorável aos pobres no processo de acumulação permeado por arcaísmos 
e relações fortemente pessoais. Aqui vemos, por mais inconsciente que seja, uma determinação da base sobre a superestrutura ou do ser social sobre a consciência, porque é de uma teia de relações sociais produtivas atrasadas e semicoloniais que emergem relações interpessoais igualmente abusivas e com pouca ou nenhuma possibilidade de reação por parte dos que partem de uma condição imensamente desfavorável na corrida pelo acesso às mercadorias e ao dinheiro. Do suicídio de Bertoleza em I890 até o suicídio de Joana em Gota d'água (I973) de Chico Buarque e Paulo Pontes, vemos mais a vitória massacrante do capitalismo subdesenvolvido e dependente brasileiro sobre indivíduos vulneráveis, mas que nem por isso deixaram de ousar lutar, do que a simples impossibilidade ou inexistência de uma rebelião por parte dos pobres.

É nesse bojo que surge outra dimensão dessa problemática representacional e que seria, sem sombra de dúvida, atualizada e sofisticada nos materialismos vindouros: a típica passividade dos pobres enxergados como objetos dos proprietários cada vez mais cederia lugar para a organização do proletariado contra os desmandos e o assalto da produção social da riqueza por parte da burguesia, ao mesmo tempo e indivisivelmente, organizada no estado e no dito mercado. Na segunda metade do século XIX isso já era uma realidade crescentemente consolidada na Europa, ao passo que, no Brasil, esse nível de articulação da luta de classes moderna ainda era muito incipiente, uma vez que o trabalho escravo era predominante. Aliás, vale insistir, este é um dado socioeconômico - o uso quase indiscriminado de mão de obra escrava por aqui - que distingue em larga medida a formação das classes fundamentais do capitalismo brasileiro e do capitalismo europeu metropolitano. Tal dado externo é tão crucial que se tornará dado interno dentro daquele processo de estruturação das obras do qual falávamos acima; isto é, o materialismo corticeiro teria como uma das suas características mais marcantes exatamente esse déficit organizacional por parte do proletariado local, o que, às vezes, representaria perdas de ordem política, teórica e estética, mas, por outro lado, muitas vezes se traduziria em um fôlego crítico maior esse materialismo que se forma por aqui, que teria muito menos ilusões a serem perdidas a respeito da harmonia da ordem social implementada tanto lá quanto cá.

Em relação ao processo de acumulação do capital, é necessário que seja dito que $O$ cortiço tem a vantagem de conferir ao fenômeno a importância devida tanto nas suas dimensões subjetivas quanto objetivas, podendo até ser sugerida uma síntese dialética desses aparentes polos que acabaria produzindo uma imagem mais abrangente do processo como um todo. Ele se concentra nos meandros do calculismo e da avareza -"Desde que a febre de possuir se apoderou dele totalmente, todos os seus atos, todos, fosse o mais simples, visavam um interesse pecuniário. Só tinha uma preocupação: aumentar os bens. Das suas horas recolhia para si e para a companheira os piores legumes, aqueles que, por maus, ninguém compraria” (AZEVEDO, 20I6, p. 23) -, nas dinâmicas da competição, do desejo de melhoramento da propriedade, das superstições em relação ao que de fato significaria aquela modernização do bairro do Botafogo e da então capital do país, da racionalidade perversa do empréstimo de dinheiro a juros, da suspensão da pose da moralidade pequeno-burguesa através do roubo sistemático que caracteriza a acumulação primitiva (João Romão anexando Bertoleza, por exemplo) e por aí vai - "Para se livrar e poder realizar o seu projeto de 
enriquecimento e ascensão social, o português do tipo João Romão precisa despir o sexo de qualquer atrativo, recusar o encantamento das Ritas Bahianas e ligar-se com a pobre Bertoleza, meio gente, meio bicho" (CANDIDO, 20I5, p. I24).

O ritmo narrativo ditado pelas artimanhas do dinheiro é outro aspecto da figuração do processo de acumulação do capital. O impasse de representar o dinheiro, ou o equivalente universal, em toda a sua abstração e subterrâneos causais, parece ser solucionado através do enquadramento dos seus efeitos; isto é, o dinheiro seria um nexo social ausente que só se revelaria de maneira adequada nos seus efeitos fosse na sua ausência, no seu excesso ou na busca obstinada por ele, como vimos mais acima no comportamento de João Romão:

\begin{abstract}
Sempre em mangas de camisa, sem domingo nem dia santo, não perdendo nunca a ocasião de assenhorar-se do alheio, deixando de pagar todas as vezes que podia e nunca deixando de receber, enganando os fregueses, roubando nos pesos e nas medidas, comprando por dez réis de mel coado o que os escravos furtavam da casa dos seus senhores, apertando cada vez mais as próprias despesas, empilhando privações sobre privações, trabalhando e mais a amiga como uma junta de bois, João Romão veio afinal a comprar uma boa parte da bela pedreira, que ele, todos os dias, ao cair da tarde, assentado um instante à porta da venda, contemplava de longe com um resignado olhar de cobiça.

Pôs lá seis homens a quebrarem pedra e outros seis a fazerem lajedos e paralelepípedos, e então principiou a ganhar em grosso, tão em grosso que, dentro de ano e meio, arrematava já todo o espaço compreendido entre as suas casinhas e a pedreira, isto é, umas oitenta braças de fundo sobre vinte de frente em plano enxuto e magnífico para construir. (AZEVEDO, 20I6, p. I6).
\end{abstract}

Nesse excerto é evidente como os longos períodos compostos pela listagem das tarefas que haviam sido realizadas obedecem à necessidade de narração de como João Romão foi acumulando capitais. É interessante observar como o trabalho, e até mesmo as "privações", estão por todo lado, mas, ao mesmo tempo, são secundarizados quando colocados lado a lado das manobras e das "espertezas" do português. O dictum capitalista, que versa sobre a diversificação de investimentos, igualmente marca presença e impõe a concentração de diversas atividades sob a mesma égide dos longos períodos, emulando o diverso a serviço de um todo que se automatiza sem deixar de se subordinar ao senhor que vai expandindo os seus negócios; lembremos que o cortiço é uma, embora imensamente importante, das fontes de renda de João Romão e que no final ele continua a ampliar essa já diversificada "carteira de investimentos" ao se casar com a filha de Miranda e atender um público acima daquele expulso após o incêndio do cortiço.

Mudando um pouco de assunto e avançando nos modos como esse materialismo corticeiro deixou um legado ambíguo. Pensemos agora sobre a retomada e a reinterpretação da determinação do meio coletivo em relação à agência individual. Evidentemente que tal determinismo mecanicista é tão problemático quanto soa aos nossos ouvidos do século XXI. No entanto, enquadrado no seu contexto, encontra alguma justificativa na batalha ideológica contra o idealismo romântico e todo o 
seu respectivo recurso à superstição, ao suprassensível, ao acaso, à primazia da espontaneidade e ao mito. Há ainda pelo menos mais uma requalificação a ser feita nessa determinação, pois, em $O$ cortiço, segundo Candido, o que era para gerar uma objetivação das relações causais que regem a vida social contraditoriamente termina por retornar a uma mistificação calcada na essencialização das ideias atribuídas às raças, bem como a uma concepção do meio não como um ambiente social, mas como um ambiente natural dado e possivelmente imutável. Com efeito, se a literatura do naturalismo poderia ser vista como uma espécie de continuadora do projeto do iluminismo humanista e liberal, no qual "as tradicionais ideias de destino, de uma ordem absoluta, de um desígnio além dos poderes humanos foram substituídas por uma confiança na razão e na possibilidade de uma capacidade continuamente ampliada para a elucidação e o controle", a verdade inconveniente é que essa "nova ênfase na observação e na descrição exatas do mundo social contemporâneo" não raramente se tornou "uma descrição mecânica dos homens como criaturas do seu meio ambiente, que a literatura registrava como se homens e coisas fossem da mesma natureza”, representando uma “deliberada restrição", para não dizer decadência, do projeto inicial do liberalismo ao rejeitar "uma prioridade humana geral, acima do processo como um todo" e junto com isso a própria possibilidade de uma revolução, de uma ruptura que saísse do esquema da observação e descrição (WILLIAMS, 2002, p. 97-99).

Isso poderia ser traduzido como uma determinação unilateralmente cultural ou, pior ainda, biológica, em relação às dinâmicas sociais, enquanto o correto seria imaginar que uma não vai sem a outra. O que estamos querendo dizer é que muito provavelmente o naturalismo tenha percorrido - e tombado diante deles - os problemas de uma leitura essencialmente empírica da efetividade e que, precisamente graças a isso, tenha desenvolvido uma visão fortemente mecanicista e arbitrária das relações interpessoais sob os auspícios da dominação do capital; se por um lado a primazia da contingência era repleta de problemas, por outro lado a primazia da necessidade também o é. É claro que esse erro deve ser visto dialeticamente e que ele não apenas pode, mas deve ser enxergado como uma lição necessária para os materialistas que vieram depois e que estavam interessados nas objetivações do intelecto. Recordemos como Candido monta o problema:

O leitor d'O cortiço fica duvidando se ele é um romance naturalista verdadeiro, que não deseja ir além da realidade observável, ou se é nutrido por uma espécie de realismo alegórico, segundo o qual as descrições da vida quotidiana contêm implicitamente um outro plano de significado. Lukács diria que isto se dá por causa daquilo, e que o mal do Naturalismo foi não "espelhar" de modo correto a realidade, mas usá-la para chegar a uma visão reificada e deformadora, que a substitui de maneira indevida e é alegórica. Não creio que assim seja e registro que a alegoria não ocorre no Naturalismo em geral. Nós não a encontramos, por exemplo, na obra de Verga nem nos romances naturalistas de Eça de Queirós; mas a encontramos sem dúvida nos de Zola, cabeça-deturco de Lukács, que a partir deles procedeu a uma extrapolação. Talvez por influência de Zola nós a encontramos também nos de Aluísio, sendo em ambos os casos, a meu ver, elemento de força e não de fraqueza. [...] 
Talvez a força do livro venha em parte desta contaminação do plano real e do plano alegórico, fazendo pensar imediatamente numa relação causal de sabor naturalista, que na cabeça dos teóricos e publicistas era: Meio Raça Brasil; e que no projeto do ficcionista foi: Natureza tropical do Rio Raças e tipos humanos misturados Cortiço. Isto é: no intuito de Aluísio a natureza que cerca o cortiço de todos os lados, com o sol queimando no alto, condiciona um modo de relacionamento entre os diversos grupos raciais, que por sua vez fazem do cortiço o tipo de aglomerado humano que é. E esta série causal encarnaria o que se passava na escala nacional, segundo as concepções do tempo. (CANDIDO, 20I5, p. II8-II9)

Não se pode, é claro, de jeito nenhum ignorar as determinações naturais do meio no que tange às relações sociais correspondentes. Com efeito, isso é algo que Caio Prado Júnior, como bom materialista, nos recorda ao afirmar que a nossa área tropical e subtropical da América nos relega uma realidade de colonização e exploração qualitativamente distinta daquela encontrada na América temperada: "é que tais condições proporcionarão aos países da Europa a possibilidade da obtenção dos gêneros que lá fazem falta. [...] Coloquemo-nos naquela Europa anterior ao século XVI, isolada dos trópicos, só indireta e longinquamente acessíveis" (PRADO JÚNIOR, I973, p. 28). Isto é, até certo ponto, a determinação naturalista do meio presente na obra de Azevedo faz todo sentido, pois ela condicionou as relações intersubjetivas e produtivas entre as diferentes classes que se instalaram aqui. De fato, "se vamos à essência da nossa formação", continua Caio Prado Júnior (I973, p. 3I), "veremos que na realidade nos constituímos para fornecer açúcar, tabaco, alguns outros gêneros; mais tarde ouro e diamantes; depois, algodão, e em seguida café, para o comércio europeu. Nada mais que isto", e termina por concluir que é “com tal objetivo, objetivo exterior, voltado para fora do país e sem atenção a considerações que não fossem o interesse daquele comércio, que se organizarão a sociedade e a economia brasileiras".

Desse modo, encontramos algumas sobre a razão de o meio se impor aos comportamentos retratados no romance funcionar mais na sua versão brasileira do que na sua matriz europeia. Não é coincidência, então, que, quando Piedade de Jesus, a portuguesa esposa do português Jerônimo, é trocada pela mestiça Rita Bahiana, ela levante "os punhos cerrados para um céu que não é instância divina, mas a Natureza excitadora, tão diversa como diz, da paisagem tranquila de sua terra, que não favorecia os sentimentos desvairados” (CANDIDO, 20I5, p. I22). Obviamente que há um prejuízo determinista, o qual interpreta os efeitos do meio nas raças e quase que automaticamente transfere para as relações sociais. Essa determinação é, a propósito, objeto de profunda reflexão por inúmeros críticos culturais, materialistas ou não, ao longo do século XX, procurando, cada um a seu modo, produzir uma síntese dessas múltiplas determinações e levando, às vezes, os erros naturalistas e tudo o que eles representavam em consideração, fosse direta ou indiretamente. Novamente chamamos atenção para o fato de que a crítica não conservadora ao naturalismo deve levar em conta o que estava por trás das necessidades representacionais da literatura naturalista em relação à ascensão do proletariado como classe e à sua respectiva luta pelo direito à representação em oposição à afetação do idealismo burguês. Isso, é claro, não extingue a crítica, mas a qualifica.

Há que ser retomado, contudo, que para Antonio Candido esse determinismo 
gerou um ganho em termos de particularidade em relação ao romance de Zola, especialmente porque L'assommoir teria ambicionado desvendar o subterrâneo do "significado humano geral" da pobreza e da exploração, enquanto $O$ cortiço teria se aproveitado da natureza extremamente exótica, exuberante e enormemente produtiva do ponto de vista agropecuário, conseguindo chegar mais perto de um equilíbrio particular ao maximizar o papel desse meio natural. Isso significa que no Brasil, apesar dos problemas, o naturalismo encontrou um terreno fértil da perspectiva da explicação causal exatamente porque, graças a questões de ordem social, histórica, geográfica e econômica, nosso território se moldou bastante em função do seu meio natural e da diversidade de raças que aqui se alojaram; processos mais ou menos análogos, mas que sem dúvida eram muito mais recentes e contavam com menos mediações, sobretudo políticas, do que na Europa, que ainda se debatia contra as persistentes amarras feudais. Há aqui um traço de grande importância para a crítica materialista nacional: não negligenciar o papel de colônia tropical exportadora do nosso país na formatação da sua história social e política. A solução representacional dessa determinação encontrada por Aluísio Azevedo em O cortiço foi um tipo de processo de autonomização do meio, conferindo não só à natureza fluminense papel determinante, mas também à própria habitação dos pobres e fonte de renda de João, uma proeminência espantosa até o ponto de ela se tornar uma personagem: "Eram cinco horas da manhã e o cortiço acordava, abrindo, não os olhos, mas a sua infinidade de portas e janelas alinhadas. Um acordar alegre e farto de quem dormiu de uma assentada sete horas de chumbo" (AZEVEDO, 20I6, p. 40).

Há ainda outra sustentação para a causalidade mecânica empregada pelo naturalismo em geral e pelo naturalismo à brasileira em particular, sem retirar a validade da crítica. Com efeito, a expansão da reificação, desumanização ou coisificação do indivíduo dentro do processo de acumulação do capital possibilita um alcance excessivo desse tipo de causalidade que transforma aspectos complexos da ordem da subjetividade e do indivíduo mais suscetíveis às determinações mecânicas de uma causa externa. Trocando em miúdos, a generalização da forma mercadoria impôs uma universalização do reino da necessidade qualitativamente distinta e que tornou o sujeito ainda mais subordinado às causalidades mecânicas da ordem da privação econômica - o exemplo mais típico desse processo foi a gradual e complexa mecanização da agricultura, que fez com que populações inteiras ficassem mais e mais dependentes do dinheiro do que do próprio trabalho como em modos de produção anteriores. Isso significa que a "a categoria da efetividade mecânica retém uma validade puramente local nas análises culturais", sobretudo se tivermos em mente "as categorias 'extrínsecas' de nosso pensamento quando estas continuam a comandar realidades objetivas a respeito das quais planejamos pensar"; mais ainda: "a causalidade mecânica é, portanto, menos um conceito que pode ser avaliado a partir de seus próprios termos do que uma das várias leis e subsistemas de nossa vida social e cultural especialmente reificada" (JAMESON, I992, p. 22-23). O que ele parece querer dizer é que, enquanto persistir a pré-história humana sob o reino da necessidade, a causalidade mecânica sempre terá uma verdade parcial e uma validade local.

Dentro do quadro do que temos chamado de materialismo corticeiro, isso se 
amplia bastante, pois aqui o naturalismo se revela ainda mais forte em termos explicativos, já que a barbárie da modernização dos ciclos de acumulação do capital somada à menor presença de ilusões a respeito do próprio sistema de dominação social propicia um grau de nitidez da realidade moderna significativamente mais apurado do que a sua versão pretensamente universal, ou europeia. Mais ainda: descrever a classe trabalhadora brasileira do final do século XIX como objeto faz muito mais sentido e ajudou Azevedo, ao passo que prejudicou Zola em L'assommoir, principalmente tendo em vista o nível organizativo muito mais elevado do proletariado francês. Se por um lado o capitalismo francês tinha uma série de variáveis que dificultava o alcance do determinismo naturalista, por outro lado a pura violência e o desmando de uma sociedade que já nasceu como fruto do desenvolvimento capitalista deram força ao materialismo corticeiro de Azevedo. Uma das vantagens desse naturalismo, como perspectiva local, reside em demonstrar os momentos de inverdade da matriz universal explicitamente, porque recoloca aquela problemática em outros termos ainda mais difíceis de se observar uma saída. Nota-se esse tipo de achatamento nas condições de vida e nas perspectivas de luta dos mais pobres onde reina a pura violência, bem como na estreiteza dos processos de aburguesamento locais. O materialismo corticeiro, então, poderia desestruturar as assim vistas como agruras do naturalismo francês, exatamente em função de ele ser uma espécie de devir negativo onde a cristalização do regime do capital e do seu autoritarismo vai desmontando uma a uma das alternativas e encurtando cada vez mais a possibilidade de agência humana - a pergunta que fica é até quando?

\section{REPRESENTATIVIDADE E CONTRADIÇÃo}

- É esta! disse aos soldados que, com um gesto, intimaram a desgraçada a segui-los. - Prendam-na! É escrava minha! A negra, imóvel, cercada de escamas e tripas de peixe, com uma das mãos espalmada no chão e com a outra segurando a faca de cozinha, olhou aterrada para eles, sem pestanejar.

Os policiais, vendo que ela se não despachava, desembainharam os sabres. Bertoleza então, erguendo-se com o ímpeto de anta bravia, recuou de um salto e, antes que

alguém conseguisse alcançá-la, já de um só golpe certeiro e fundo rasgara o ventre de lado a lado.

E depois emborcou para frente, rugindo e esfocinhando moribunda numa lameira de sangue. João Romão fugira até ao canto mais escuro do armazém, tapando o rosto com as mãos.

Nesse momento parava à porta da rua uma carruagem. Era uma comissão de abolicionistas que vinham, de casaca, trazer-lhe respeitosamente o diploma de sócio benemérito.

Ele mandou que os conduzissem para a sala de visitas. (Aluísio Azevedo, O cortiço, p. 292). 
Há que ser dito, contudo, que há uma contradição de fundo e que hoje em dia se faz sentir com muita força: a questão da representação, ou melhor dizendo, dos altos e baixos da ênfase na representatividade de uma determinada classe social. Esta problemática importa porque funcionou como uma espécie de legado ambivalente para uma série de formações ideológicas no século XXI, para certa crítica cultural materialista do século XX e para uma parte das principais frações políticas do século XIX, que se filiavam, de diferentes maneiras e com incontáveis consequências práticas, ao ponto de vista da luta do proletariado contra a ordem burguesa, que ia se consolidando. Ambíguo porque, embora tenha sido reconhecido positivamente, notadamente por Bertolt Brecht, que já na década de I920 dizia que muitos dos assuntos e dos temos do teatro épico ligados à vida e à luta dos trabalhadores haviam sido trabalhados pelo naturalismo, ele também foi injustamente criticado por estabelecer algum idealismo romantizado no que tange à pauperização, à índole dos de baixo, certas causalidades arbitrárias, uma confiança demasiada nas teorias que predicavam comportamentos para certas classes, etnias, raças, identidades desviantes e assim por diante. A questão é que o naturalismo parece ter sido um momento de experimentalismo estético que buscou inovar a convenção tacanha e privatista da burguesia oitocentista, colocando assuntos sociais, políticos e econômicos fundamentais para as grandes maiorias, e uma das razões daquela escola ter se mostrado sensível a essas questões é porque, como já dito anteriormente, o naturalismo é causa e resultado da luta do proletariado europeu por uma representatividade não só política, mas também estética.

Se pensarmos que a luta social e política de uma classe inevitavelmente cria as condições de possibilidade para um front também no campo da construção simbólica, logo, a luta, a conquista e a consolidação da representação estética da burguesia enquanto classe ao longo do século XVIII e do proletariado ao longo do século XIX também podem ser vistas dentro desse quadro. Não se trata de uma luta completamente consciente, mas de um dado da realidade que se impõe aos intelectuais e artistas nos seus respectivos processos de estruturação de suas obras. Isto é, a proeminência que determinados atores sociais ganham ao longo da expansão qualitativa e quantitativa de suas ações, com toda certeza, os coloca no horizonte das formalizações do pensamento de outrem e deles mesmos.

Esquematicamente falando, um romance como Dom Quixote (I605; I6I5), de muitas maneiras, estrutura o enfraquecimento das práticas, modos de ver, valores e significados que sustentavam os romances de cavalaria de que ele se apropria para ridicularizá-los, bem como a ascensão do romance inglês, especialmente com a publicação de Robinson Crusoé (I7I9), também está, de diferentes modos, ligada ao ganho de importância do que eram até então as classes médias através das suas variadas revoluções políticas, religiosas, sociais e industriais. De modo mais ou menos semelhante, o surgimento da multidão metropolitana, das massas citadinas, do proletariado industrial foi incorporado como elemento interno das obras desde os contos de Edgar Allan Poe, dos poemas de Baudelaire (BENJAMIN, 20I5, p. II7-I27) e das pinturas dos impressionistas franceses (CLARK, I999, p. I47-I48) até o naturalismo, passando pelo romance social inglês. Todos, não por acaso, oitocentistas.

Essa tese, brevemente exposta, diz respeito às relações entre lutas de classe e 
as suas correspondentes representações, sejam elas pictóricas, sejam dramáticas ou narrativas. Contudo, apesar da representação ser uma etapa fundamental na compreensão de qualquer fenômeno, ela também enseja uma série de problemáticas que não são absolutamente secundárias, principalmente no advento de se transformarem em bandeiras políticas pela representação em si e para si. Com efeito, Antonio Candido em "De cortiço a cortiço" já havia notado muitos problemas dessa atividade e destaca um em particular que se concentra na quase caricatura de tipos sociais, como a mulata permissiva, o português ganancioso e por aí vai. A representatividade de grupos sociais, ou da realidade empiricamente observável, não garante em si um ganho estético ou crítico; muito pelo contrário, pois, caso não sejam muito bem pensadas, podem terminar por jogar água no moinho até mesmo de expressões ideológicas que buscava combater.

É nesse sentido que devemos nos indagar: até que ponto o conhecimento das condições da situação dos pobres, de um ponto de vista dessa mesma situação, significa necessariamente um ganho da perspectiva estética ou política e não está passível de se transformar em um simples apelo à representatividade em si e para si? O projeto naturalista de observar e retratar as dinâmicas de acumulação e de estruturação de classes, tal como elas pretensamente eram, e preferencialmente a partir da dinâmica unilateral entre necessidade do meio e agência humana, fosse ela individual ou coletiva, é sem dúvida um ganho na ampliação do cabedal de materiais e formas de representação. Entretanto, no instante em que se instaura um regime de verdade pretensamente científico ou, melhor dizendo, de realismo social, psicológico e fotográfico, limita-se fatalmente os meios representacionais, como se uma tematização dos conflitos sociais ou de determinados extratos em situação de penúria fosse em si a garantia de uma solução estética e crítica satisfatória sem maiores problemas. Isto é, nota-se uma retração do ímpeto de explicação para a mera descrição das situações.

O que queremos dizer é que um autor como Machado de Assis, por exemplo, alcançou resultados artísticos e críticos muito mais ambiciosos, segundo Roberto Schwarz, justamente quando trocou o ponto de vista do qual narrava - a conhecida "viravolta operada nas Memórias" -, transitando do olhar conformista do mais pobre que manobrava para subir para quem estava de fato com a palavra na sociedade, isto é, do branco dependente do favor para o proprietário caprichoso em meio ao escravagismo brasileiro (SCHWARZ, 2008, p. 226-228). Provavelmente foi tendo também isso em vista que críticos literários como Walter Benjamin e Raymond Williams perceberam os riscos de uma concepção de realismo essencialmente calcada na representatividade. Na década de I930, Benjamin percebeu que a "nova objetividade" na esfera da fotografia, bem como seus correspondentes literários, acabavam por "transformar a miséria num objeto de consumo... objetos de distração, do lazer... um objeto de prazer contemplativo" (BENJAMIN, 20I7, p. 94-95), já que simplesmente enquadrar a pobreza e as suas mazelas não se traduzia em uma atitude crítica e com conhecimento de causa. Já nas primeiras décadas do século $\mathrm{XX}$ se podia notar uma tendência do mercado cultural capitalista de absorver esses temas, sobretudo caso se limitassem à simples e pura representatividade, excluindo a ligação daquelas imagens com os negócios, os valores e as práticas burguesas. De 
modo semelhante, Raymond Williams, nos anos I950, caracterizou o foco narrativo do romance industrial inglês Norte e sul (I855) de Elizabeth Gaskell como um típico "observador solidário" de uma sulista, filha de um clérigo e chocada com os horrores sociais causados pelas fábricas do norte, deslocando a exploração capitalista quase que para um nível essencialmente moral e redentor ao se envolver com um industrial e persuadi-lo a humanizar ou "melhorar as relações humanas na fábrica", o que ele termina por aceitar, pois já estava "afetado pela delicadeza e humanidade superiores do sul” (WILLIAMS, I975, p. IO3). Essa ilustração demonstra como a maneira pela qual certo conteúdo é enquadrado importa e muito, uma vez que é na forma como se retrata algo que se repõem, se rejeitam ou se inauguram modos políticos de ser e de ver.

Mais ainda: será mesmo que é somente a partir de uma construção de objetividade das relações que se alcançam uma compreensão e um desafio para as mesmas? Ao analisar a poesia lírica de Charles Baudelaire e ao destrinchar os procedimentos da memória involuntária de Marcel Proust, Walter Benjamin nos demonstra que uma aposta na subjetivação e na abstração estéticas também pode ter um enorme potencial de realizar uma crítica dura à concretude burguesa como a ordem natural das coisas e como objetividade que se apresenta como dinâmica, mas que é, no seu âmago, profundamente estática de inúmeras maneiras. Por mais que a modernização capitalista goste de ver a si própria como pura diferença, heterogeneidade, contingência e inovação, aquele lirismo - apesar de qualquer eventual crítica que sem sombra de dúvida possa e deva ser feita contra ele - mostra da maneira mais dolorosa como o que há no capitalismo é mesmice e homogeneidade, porque o reino da necessidade da luta pela sobrevivência material e o correspondente fenecer do espaço do lírico são sempre cinicamente repostos.

Tudo isso nos leva à conclusão de que o naturalismo europeu e o brasileiro são momentos da maior importância para os materialismos que têm se consolidado ao oferecer explicações de mundo para os incontáveis fenômenos da sociedade regida pelo dinheiro. Esse legado parece ser inegável inclusive sob a luz dos erros, ingenuidades e exageros naturalistas, pois eles terminaram por possibilitar uma série de discussões de cunho teórico, estético e analítico que com certeza auxiliaram na formação dos materialismos que conhecemos hoje.

Por fim, não se pode perder de vista que, em razão da importação dos paradigmas representacionais europeus por parte de um país de economia dependente, acontece um fenômeno não muito incomum que é a exposição dos momentos de verdade e de falsidade do protótipo do país central. Isso equivale a afirmar que o respeito ao conteúdo sócio-histórico brasileiro necessariamente implica uma exacerbação da forma forjada na realidade metropolitana, principalmente uma vez que ela acaba por jogar luz em uma faceta daquela mesma realidade que é invisível naquele lugar; o ponto de vista da periferia preenche as lacunas das bases de sustentação daquela sociedade que se tornaram, por alguma razão ou por outra, invisíveis, gerando, assim, um olhar ainda mais crítico e com menos ilusões a respeito das falsas alternativas produzidas no centro. Claramente que isso não se traduz em um tipo de privilégio epistemológico inato, mas, em vez disso, em uma visão quase que necessariamente comparatista e mais habituada com um tipo particular de negativo. Temos chamado tal perspectiva particular do naturalismo à brasileira de materialista, porém um 
materialismo que, além de filosófico e cultural, é socialmente corticeiro e que fabrica seus melhores momentos não na mera efetivação do direito à representação, mas no exame crítico e menos idealizado da vida sob o regime do capital.

\section{SOBRE O AUTOR}

LINDBERG S. CAMPOS FILHO é doutorando em Letras no Programa de Pós-Graduação em Estudos Linguísticos e Literários em Inglês do Departamento de Letras Modernas da Faculdade de Filosofia, Letras e Ciências Humanas da Universidade de São Paulo (DLM/FFLCH/USP). Email: lindberg.filho@usp.br https://orcid.org/0000-0003-0087-0295

\section{REFERÊNCIAS}

AZEVEDO, Aluísio. (I89o). O cortiço. São Paulo: Penguin \& Companhia das Letras, 2016.

BENJAMIN, Walter. Sobre alguns motivos na obra de Baudelaire. In: . Baudelaire e a modernidade.

Trad. João Barreto. São Paulo \& Belo Horizonte: Autêntica, 20I5, p. I03-I49.

. O autor como produtor. In: . Ensaios sobre Brecht. Trad. Claudia Abeling. São Paulo: Boitempo, 20I7, p. 85-99.

BUARQUE, Chico e PONTES, Paulo. Gota d'água: uma tragédia brasileira. Rio de Janeiro: Civilização brasileira, 20I7.

CANDIDO, Antonio. Crítica e sociologia. In: . Literatura e sociedade. 9. ed. Rio de Janeiro: Ouro sobre Azul, 2006, p. I3-26.

. De cortiço a cortiço. In: . O discurso e a cidade. 5. ed. Rio de Janeiro: Ouro sobre Azul, 20I5, p. I07-I32.

CERVANTES, Miguel de. Dom Quixote de la Mancha. Trad. Ernani Ssó. São Paulo: Companhia das letras, $20 I 5$.

CLARK, T. J. The environs of Paris. In: . The painting of modern life: Paris in the art of Manet and his followers. New Jersey: Princeton University Press, I999, p. I47-I48.

DEFOE, Daniel. Robinson Crusoe. London: Penguin, 2003.

JAMESON, Fredric. A interpretação: a literatura como ato socialmente simbólico. In: O Oinconsciente político: a narrativa como ato socialmente simbólico. Trad. Valter Lellis Siqueira. São Paulo: Editora Ática, I992, p. I5-I03. (I98I)

PRADO JÚNIOR, Caio. Formação do Brasil contemporâneo. I3. ed. São Paulo: Brasiliense, I973.

SCHWARZ, Roberto. (I990). Um mestre na periferia do capitalismo: Machado de Assis. 4. ed. São Paulo: Editora 34/Livraria Duas Cidades, 2008.

SEREZA, Haroldo C. O Brasil na internacional naturalista: adequação da estética, do método e da temática 
naturalistas no romance brasileiro do século I9. $27 \mathrm{I}$ f. Tese (Doutorado em Letras). Faculdade de Filosofia, Letras e Ciências Humanas, Universidade de São Paulo, 2012.

WILLIAMS, Raymond. (I958). The industrial novels. In: . Culture and society I780-I950. London:

Penguin, I975, p. 99-II9.

. Drama from Ibsen to Brecht. London: Pelican Books, I983.

Tragédia e revolução. In: Tragédia moderna. Trad. Betina Bischof. São Paulo: Cosac Naify, 2002, p. 89-II4. 